\title{
Fault interaction and stress triggering of twentieth century earthquakes in Mongolia
}

Fred Pollitz

U.S. Geological Survey, Menlo Park, California, USA

Mathilde Vergnolle

UMR 6526 CNRS Géosciences Azur, University of Nice, Valbonne, France

Eric Calais

Department of Earth and Atmospheric Sciences, Purdue University, West Lafayette, Indiana, USA

Received 27 December 2002; revised 28 May 2003; accepted 25 June 2003; published 25 October 2003.

[1] A cluster of exceptionally large earthquakes in the interior of Asia occurred from 1905 to 1967: the 1905 M7.9 Tsetserleg and M8.4 Bolnai earthquakes, the $1931 \mathrm{M8.0} \mathrm{Fu}$ Yun earthquake, the 1957 M8.1 Gobi-Altai earthquake, and the 1967 M7.1 Mogod earthquake (sequence). Each of the larger $(M \geq 8)$ earthquakes involved strike-slip faulting averaging more than $5 \mathrm{~m}$ and rupture lengths of several hundred kilometers. Available geologic data indicate that recurrence intervals on the major source faults are several thousands of years and distances of about $400 \mathrm{~km}$ separate the respective rupture areas. We propose that the occurrences of these and many smaller earthquakes are related and controlled to a large extent by stress changes generated by the compounded static deformation of the preceding earthquakes and subsequent viscoelastic relaxation of the lower crust and upper mantle beneath Mongolia. We employ a spherically layered viscoelastic model constrained by the 1994-2002 GPS velocity field in western Mongolia [Vergnolle et al., 2003]. Using the succession of twentieth century earthquakes as sources of deformation, we then analyze the time-dependent change in Coulomb failure stress $\left(\Delta \sigma_{f}\right)$. At remote interaction distances, static $\Delta \sigma_{f}$ values are small. However, modeled postseismic stress changes typically accumulate to several tenths of a bar over time intervals of decades. Almost all significant twentieth century regional earthquakes $(M \geq 6)$ with well-constrained fault geometry lie in positive $\Delta \sigma_{f}$ lobes of magnitude about +0.5 bar. Our results suggest that significant stress transfer is possible among continental faults separated by hundreds of kilometers and on timescales of decades. INDEX TERMS: 8107 Tectonophysics: Continental neotectonics; 8123 Tectonophysics: Dynamics, seismotectonics; 8164 Tectonophysics: Stresses — crust and lithosphere; 9320 Information Related to Geographic Region: Asia; KEYWORDS: stress transfer, viscoelastic, earthquake cluster, Mongolia, postseismic

Citation: Pollitz, F., M. Vergnolle, and E. Calais, Fault interaction and stress triggering of twentieth century earthquakes in Mongolia, J. Geophys. Res., 108(B10), 2503, doi:10.1029/2002JB002375, 2003.

\section{Introduction}

[2] Triggering of earthquake sequences by transfer of static stress from previous earthquakes is well documented in many regions [King et al., 1994; Stein, 1999]. Most examples consider the triggering of aftershocks from main shocks over timescales of a few months to a few years and interaction distances up to $100 \mathrm{~km}$ [Harris, 1998]. It is found that the spatial distribution of aftershocks is well explained in terms of a Coulomb failure criterion [King et al., 1994] that involves a linear combination of the shear and normal tractions from a primary earthquake evaluated on a secondary fault plane. (Counterexamples, though

Copyright 2003 by the American Geophysical Union. 0148-0227/03/2002JB002375\$09.00 relatively few, may be noted [Astiz et al., 2000; Bennett et al., 1995; Dodge et al., 1995; Du and Aydin, 1993].) The time dependence of aftershock occurrence is less well understood, with chief candidate processes being rate- and state-dependent friction [Gross and Kisslinger, 1997; Gross and Bürgmann, 1998; Price and Bürgmann, 2002], dissipation of pore fluid gradients [Jaume and Sykes, 1992], and viscoelastic relaxation of the lower crust and mantle [Deng et al., 1999].

[3] Long range triggering of earthquakes in space or time, or both, is less well documented. Intriguing examples include (1) remote triggering of earthquakes within a few minutes or hours after the 1992 Landers earthquake [Hill et al., 1993] (long distance, short time), (2) triggering of the 1995 Kobe earthquake by stress changes following the 1944 and 1946 megathrust events off central Honshu, Japan 
[Pollitz and Sacks, 1997] and triggering of Pacific megathrust earthquakes from inland earthquakes in northern Honshu [Rydelek and Sacks, 1990] (intermediate distance, long time), (3) triggering of the 1999 Hector Mine earthquake by the 1992 Landers earthquake [Freed and Lin, 2001; Zeng, 2001; Pollitz, 2002] (short distance, long time), and (4) a southward migration of seismic activity along the western North American margin from the 1970s to 1990s following the 1952 Kamchatka-1957 Aleutian-1964 Alaskan-1965 Rat Island earthquake sequence [Pollitz et al., 1998], a southward migration of seismic activity along the San Jacinto fault in the decades following the 1857 Fort Tejon earthquake [Sanders, 1993; Rydelek and Sacks, 2001], and clustering of earthquakes in Mongolia [Chéry et al., 2001b] (long distance, long time). The post-Landers activity in the western United States investigated by Hill et al. [1993] has been attributed to dynamic stresses upon passage of the seismic waves generated by the Landers earthquake. All other quoted examples have been attributed to viscoelastic relaxation of the lower crust and upper mantle in continental regions or to the oceanic asthenosphere in the case of the western North America triggered seismicity. Although evidence from well-documented examples continues to mount for short time or short range triggering, relatively little evidence exists for stress triggering among continental earthquakes at both long distance and long time.

[4] A sequence of exceptionally large earthquakes occurred in the interior of Asia from 1905 to 1967 (Figure 1). The largest of these, the M8.4 1905 Bolnai earthquake, is one of the largest continental intraplate earthquakes to have occurred in historic times [Okal, 1977], with 8 to $11 \mathrm{~m} \pm 2 \mathrm{~m}$ horizontal displacement over a $375 \mathrm{~km}$ long left-lateral strike-slip fault [Baljinnyam et al., 1993]. Each earthquake in this sequence involved strike-slip faulting of several meters and rupture lengths of several hundred km. Available geologic data indicate that geologic slip rates are very small, on the order of $1-3 \mathrm{~mm} / \mathrm{yr}$ on the faults which ruptured in the twentieth century. If, in particular, the Bolnai and Bogd faults accommodate most of the regional accumulated left lateral strain, as suggested by the maturity of these structures [Cunningham, 1998], then earthquakes as large as those which occurred in the twentieth century should occur about every 2000 to 8000 years. This is roughly in accord with estimated recurrence intervals on the Bolnai fault (D. Schwartz, personal communication, 2001; J. F. Ritz, personal communication, 2001) and Bogd fault [Ritz et al., 2003] based on paleoseismic investigation. This raises the question as to how so many large earthquakes in this region could occur within a relatively narrow time interval. Distances of several hundred $\mathrm{km}$ separate the ruptures in question, and times between succeeding events are 26 years (1905 to 1931 and 1931 to 1957 ) for the larger ruptures and generally several decades for the smaller twentieth century earthquakes.

[5] If the clustering of these earthquakes in time is not coincidental, then a long range triggering mechanism must be sought. On the basis of previous experience, we regard the most promising mechanism to be stress changes generated by the compounded static deformation of these earthquakes and viscoelastic relaxation of the lower crust and upper mantle beneath Mongolia. Chéry et al. [2001b] pointed out that this mechanism has the potential to account

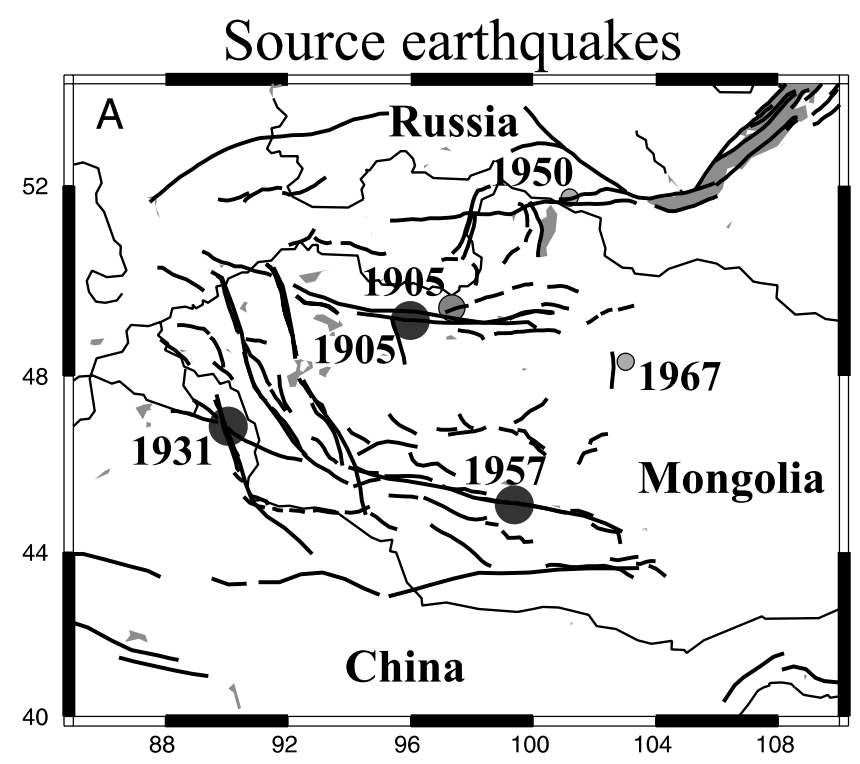

\section{Potentially triggered earthquakes}

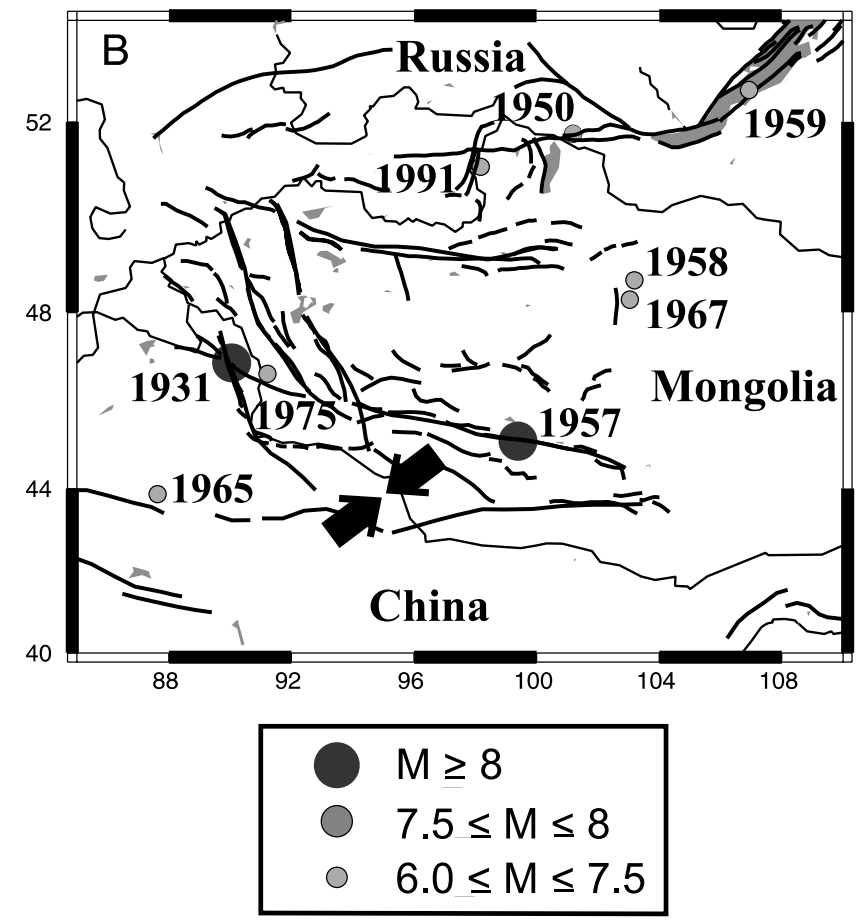

Figure 1. Major faults of Mongolia and northwest China and epicenters of major (a) source (primary) and (b) potentially triggered (secondary) earthquakes considered in this study. Approximate direction of maximum horizontal stress is indicated by black arrows. All catalog events [Bayasgalan, 1999; Bayasgalan and Jackson, 1999] of $M \geq 7$ since 1905 are shown in Figure 1a, and events $M \geq 6$ since 1905 are shown in Figure 1b. The potentially triggered earthquakes in Figure 1b are classified as "non-Baikal" or "Baikal" events according to their location. Specifically, the 1950 and 1959 events are classified as "Baikal" events because they occurred in a likely different tectonic regime than the remaining "non-Baikal" (Mongolian/western China) events. 


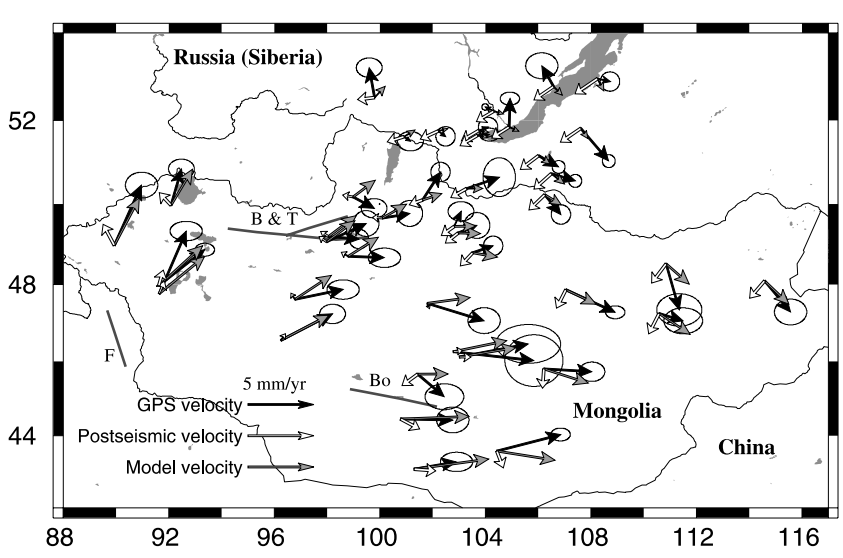

Figure 2. GPS velocity field in Mongolia [Vergnolle et al., 2003] shown by black velocity vectors and $95 \%$ confidence ellipses. This velocity field is well explained as the superposition of pure shear and the viscoelastic relaxation of the lower crust and upper mantle following several large twentieth century earthquakes [Vergnolle et al., 2003]. Superimposed are current predicted total velocity (grey arrows) and the contribution from postseismic relaxation calculated on model A (see text) (white arrows). Black line segments are selected fault traces: B \& T, 1905 Bolnai and Tsetserleg earthquakes; F, 1931 Fu Yun earthquake; Bo, 1957 Gobi-Altai earthquake (Bogd fault).

for both the long range distances between succeeding earthquakes as well as the long times involved. They made a good case for the importance of the relaxation mechanism in triggering two of the larger earthquakes (the $1931 \mathrm{Fu}$ Yun and 1957 Gobi-Altai earthquakes). The primary earthquakes driving viscoelastic stress changes in their study were the 1905 Bolnai and $1931 \mathrm{Fu}$ Yun earthquakes (the Fu Yun earthquake acts as both a primary and a triggered earthquake). They evaluated the coseismic and completely relaxed postseismic stress states and used an approximate relationship (their equation (6)) to evaluate the time dependence of relaxation between these two states. Their approximate relationship does not account for the dispersion of characteristic relaxation time with respect to wavelength (a general property of viscoelastic models, e.g., Figure 2 of Pollitz [1997]), but it does allow them to address the question of how interevent delay times of several decades can be rationalized. In the present study we analyze the proposed mechanism in greater detail by accounting for the stress contributions of several potentially important primary earthquakes, considering the time-dependent predictions of a viscoelastic model constrained by the GPS velocity field in Mongolia, and evaluating these predictions at the nucleation points of several large $(M \geq 6)$ twentieth century earthquakes in Mongolia and western China. The results will show that the locations of some $M \geq 6$ regional earthquakes during the twentieth century are well correlated with positive Coulomb stress changes, most of which is attributable to viscoelastic relaxation of a ductile mantle.

\section{Viscoelastic Stratification}

[6] Global Positioning System (GPS) data collected from 1994 to 2002 (Figure 2) place important constraints on the active tectonics of Mongolia and the Baikal Rift region [Calais et al., 2003]. Modeling of this data [Vergnolle et al., 2003] suggests that the present-day velocity field is shaped by both background tectonic motions and continued viscoelastic relaxation of the region generated by the sequence of twentieth century earthquakes. Although there is uncertainty as to the relative contributions of these two processes, current modeling suggests a range of viscoelastic models which may account for some of the signal in the velocity field. Among the models consistent with the GPS data, we work with two candidate viscoelastic models depicted in Figure 3 . They are characterized by a $35 \mathrm{~km}$ thick upper crust, a $15 \mathrm{~km}$ thick uniform and ductile lower crust, a uniform and weak upper mantle down to $220 \mathrm{~km}$ depth, and an uniform strong (assumed elastic) mantle below $220 \mathrm{~km}$ depth.

[7] The existence of a weak mantle beneath the region is supported by the normal to high heat flow values in northern/ central Mongolia [Khutorskoy and Yarmoluk, 1989] with respect to typical cratonic heat flow, the presence of relatively slow upper mantle seismic velocities beneath central Asia [Levshin et al., 1996; Villaseñor et al., 2001; Friederich, 2003], elevated uppermost mantle temperatures as constrained by mantle xenoliths [Ionov et al., 1998], and the instantaneous velocity field as constrained by recent GPS data [Vergnolle et al., 2003]. Referring to Figure 3, the viscosity values of $\eta_{m}=2 \times 10^{18} \mathrm{~Pa} \mathrm{~s}$ or $\eta_{m}=10^{18} \mathrm{~Pa} \mathrm{~s}$ considered here are similar to those derived by Kaufmann and Amelung [2000] and Nishimura and Thatcher [2003] in the Basin and Range Province and Pollitz et al. [2001] in the Mojave Desert. Although the lower crust viscosity is less well constrained by the GPS data set, we consider two values: $\eta_{c}=10^{20} \mathrm{~Pa} \mathrm{~s}$ and $\eta_{c}=1.5 \times 10^{17} \mathrm{~Pa} \mathrm{~s}$; the larger

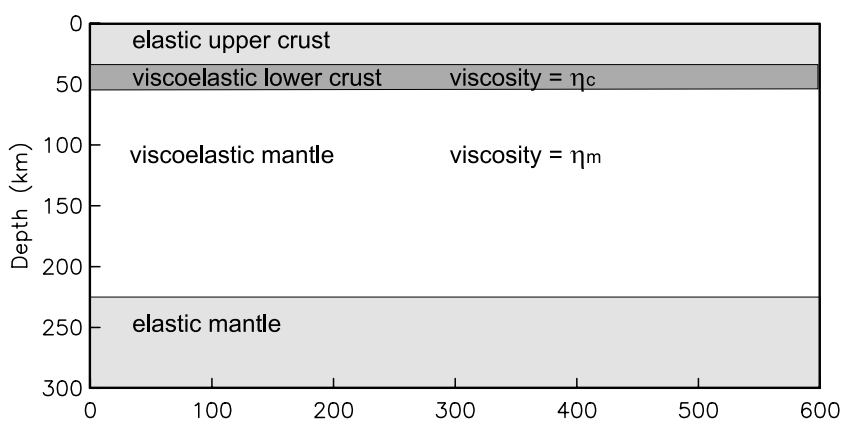

Figure 3. Viscoelastic stratification of the study region. It is characterized by a purely elastic upper crust, Maxwell viscoelastic lower crust of viscosity $\eta_{c}$, and Maxwell viscoelastic upper mantle of viscosity $\eta_{m}$. The mantle is assumed elastic below $220 \mathrm{~km}$ depth. Total crustal thickness is based on thermobarometric and petrologic analysis of mantle and lower crustal xenoliths in western Mongolia [Ionov et al., 1998] and the northern Hangai area [Stosch et al., 1995; Kopylova et al., 1995], seismic tomography [Villaseñor et al., 2001], and forward modeling of gravity data [Petit et al., 2002]. All layers except the upper crust are assigned uniform elastic parameters and viscosity. Two models are considered in this paper. Model A (weak crust, weak mantle): $\eta_{c}=1.5 \times 10^{17} \mathrm{~Pa} \mathrm{~s}, \eta_{m}=2.2 \times 10^{18} \mathrm{~Pa} \mathrm{~s}$. Model B (strong crust, weak mantle): $\eta_{c}=1.0 \times 10^{20} \mathrm{~Pa} \mathrm{~s}$, $\eta_{m}=1.0 \times 10^{18} \mathrm{~Pa} \mathrm{~s}$. 
value is similar to that derived for the lower crust in the Basin and Range Province [Kaufmann and Amelung, 2000; Nishimura and Thatcher, 2003]. Regional studies [Stosch et al., 1995; Kopylova et al., 1995; Ionov et al., 1998; Déverchère et al., 2001] indicate that the lower crust may be composed of diabase, and extrapolation of the geotherm of Ionov et al. [1998] combined with application of flow laws for wet diopside or dry diabase [Mackwell et al., 1998] support the model of a relatively strong lower crust. However, modeling of regional GPS data points to a much weaker crust [Vergnolle et al., 2003]. Vergnolle et al. [2003] argue that a very weak crust beneath $35 \mathrm{~km}$ depth is consistent with $\sim 800-850^{\circ} \mathrm{C}$ temperatures inferred at that depth if a quartzite rheology, perhaps in conjunction with the presence of partial melt, is applicable, or if a transient rheology [Ivins, 1996] has affected the evolution of the region since the occurrence of the twentieth century earthquakes. Although measured heat flow values and constraints on the composition of the lower crust could help resolve which crustal viscosity is more appropriate, the uncertainty associated with these issues and with extrapolating heat flow to depth [Chapman and Furlong, 1992] leads us to explore both values of $\eta_{c}$. Our consideration of different $\eta_{c}$ shows that, as long as the mantle is relatively weak, the value of crustal viscosity exerts only a small influence on the resulting stress evolution pattern. Of greater importance is the existence of a weak upper mantle, which gives our fault interaction model the capability of extending the spatial domain of significant postseismic strain. We shall refer to the viscoelastic models $\left\{\eta_{m}=2.2 \times 10^{18} \mathrm{~Pa} \mathrm{~s}, \eta_{c}=1.5 \times\right.$ $\left.10^{17} \mathrm{~Pa} \mathrm{~s}\right\}$ and $\left\{\eta_{m}=10^{18} \mathrm{~Pa} \mathrm{~s}, \eta_{c}=10^{20} \mathrm{~Pa} \mathrm{~s}\right\}$ with low and high $\eta_{c}$ as model $\mathrm{A}$ and model $\mathrm{B}$, respectively. Figure 2 includes the instantaneous velocity field from postseismic relaxation of significant twentieth century earthquakes calculated on model $\mathrm{A}$; the magnitude of postseismic velocity persists at $2 \mathrm{~mm} / \mathrm{yr}$ at present.

[8] For a given viscoelastic model and fault geometries of primary earthquakes, static and viscoelastic deformation are calculated using the methods of Pollitz [1996] and Pollitz [1997], respectively. In particular, the method of Pollitz [1997] employs a decomposition of the total postseismic deformation field into a truncated sum of spheroidal and toroidal viscoelastic normal modes. In concert, these methods prescribe the exact time-dependent response of a spherically stratified viscoelastic medium to a point source of deformation in one of the elastic layers. The response to a finite fault is realized in these methods by numerical integration of a sufficient number of point sources distributed over the fault plane(s).

\section{Stress Evolution}

\subsection{Coulomb Failure Stress}

[9] Using the succession of twentieth century Mongolian earthquakes as sources of deformation, we evaluate the evolution of Coulomb failure stress $\Delta \sigma_{f}$ over a $100,000 \mathrm{~km}^{2}$ area encompassing these earthquakes. This is defined as

$$
\Delta \sigma_{f}=\Delta \tau+\mu_{\mathrm{eff}} \Delta \sigma_{n}
$$

where $\Delta \tau$ and $\Delta \sigma_{n}$ are the change in tensor shear and normal stress on a defined secondary fault plane and $\mu_{\text {eff }}$ is the effective coefficient of friction, which we assume for simplicity to include the possible effect of changes in pore pressure in the secondary fault zone [King et al., 1994]. The shear stress equals the traction resolved on an assumed slip vector within the secondary fault plane, and the normal stress equals the traction resolved on the normal vector to the secondary fault plane. The coefficient of friction is commonly found to be 0.6 to 0.8 for laboratory samples [Lachenbruch and McGarr, 1990], but in stress triggering studies it is inferred to range anywhere from 0 to 0.8 . Stein [1999] noted that smaller/larger values of $\mu_{\text {eff }}$ appear to be correlated with the maturity/immaturity of the secondary fault zone. In our analysis we considered values of $\mu_{\text {eff }}$ of 0 , 0.4 , and 0.8 . Stress changes on all receiver faults are found sensitive to this value, with values of 0.4 to 0.8 generally yielding stronger correlations of earthquake occurrence with $\Delta \sigma_{f}$. For concreteness, we shall fix $\mu_{\text {eff }}$ at 0.4 in most cases. Note that $\Delta \sigma_{f}$ depends on time as well as location because of the contribution of viscoelastic relaxation following each of the primary earthquakes. Critical parameters controlling the stress evolution are the fault parameters of the primary earthquakes (length, strike, dip, rake, slip), the viscoelastic stratification, and the geometry of the secondary plane(s). The locations of primary earthquakes and secondary earthquakes (some of which are themselves primary earthquakes) are shown in Figures 1a and 1b, respectively. The primary earthquakes are all regional earthquakes listed by Bayasgalan [1999] or Bayasgalan and Jackson [1999] of magnitude 7.0 or greater occurring since 1905. The secondary earthquakes occurred from 1931 to 1991 , and the 1905 Tsetserleg/Bolnai earthquakes are the earliest occurring source earthquakes. Table 1 of Vergnolle et al. [2003] lists the fault parameters of all primary earthquakes, and Table 1 of this paper lists the fault plane solutions of the secondary earthquakes, which are all regional earthquakes of magnitude 6.0 or greater listed in Table 2.1 of Bayasgalan [1999]. The slip vectors listed in Table 1 likely represent the sense of motion at the nucleation point. These were determined from geologic mapping of the surface ruptures and first-motion analysis of seismograms. This affords us the opportunity to examine if triggering of the overall rupture or the nucleation point (or both) is consistent with the calculated stress evolution. We shall evaluate the cumulative $\Delta \sigma_{f}$ at various times starting with just after the 1905 Tsetserleg/Bolnai earthquakes and continuing to just before the earthquakes. The orientation of the secondary fault plane corresponds in all cases to the earthquake which occurred at the considered time, i.e., the fault geometry of the $1931 \mathrm{Fu}$ Yun earthquake defines the secondary fault geometry for the $\Delta \sigma_{f}$ evaluation just before 1931. Given the large ( $48 \mathrm{~km})$ crustal thickness in the region [Stosch et al., 1995; Kopylova et al., 1995; Ionov et al., 1998; Petit et al., 2002] and the occurrence of earthquakes as deep as $30 \mathrm{~km}$ [Bayasgalan, 1999], we evaluate all changes in $\Delta \sigma_{f}$ at depth $20 \mathrm{~km}$.

\subsection{Conceptual Model of Postseismic Triggering}

[10] It is henceforth assumed that background loading in the study region is negligible compared with other factors. The observed GPS velocity field (black arrows in Figure 2) exhibits a gentle north-south velocity gradient which, if uniform, would yield a background stressing rate of only $\sim 0.003 \mathrm{bar} / \mathrm{yr}$. The expected 0.15 bar contribution over a 
Table 1. Focal Mechanism Solutions of Secondary Earthquakes

\begin{tabular}{|c|c|c|c|c|c|c|}
\hline Earthquake & Date & Strike & Dip & Rake & Magnitude & Reference \\
\hline Fu Yun & 10 Aug. 1931 & 161 & 90 & 180 & $M_{w} 8.0$ & Khilko et al. [1985] \\
\hline Mondy (Baikal) & 4 April 1950 & 100 & 75 & 000 & $M_{w} 7.0$ & Delouis et al. [2002] \\
\hline Gobi-Altai $^{\mathrm{a}}$ & 4 Dec. 1957 & 103 & 53 & 32 & $M_{w} 8.1$ & Okal $[1976]$ \\
\hline Gobi-Altai $^{\text {b }}$ & 4 Dec. 1957 & 101 & 70 & 009 & $M_{w} 8.1$ & Kurushin et al. [1997] \\
\hline - & 23 June 1958 & 1 & 70 & 151 & $m_{b} 6.2$ & Khilko et al. [1985] \\
\hline (Baikal) & 29 Aug. 1959 & 248 & 53 & -50 & $m_{b} 6.8$ & Doser [1991] \\
\hline- & 13 Nov. 1965 & 269 & 52 & 105 & $m_{b} 6.3$ & Tapponnier and Molnar [1979] \\
\hline Mogod & 5 Jan. 1967 & 020 & 90 & 165 & $M_{w} 7.1$ & Bayasgalan and Jackson [1999] \\
\hline- & 31 March 1975 & 180 & 70 & 135 & $m_{b} 6.0$ & Tapponnier and Molnar [1979] \\
\hline Busingol & 27 Dec. 1991 & 246 & 80 & -8 & $M_{w} 6.3$ & Bayasgalan [1999] \\
\hline
\end{tabular}

${ }^{\mathrm{a}}$ First-motion mechanism.

${ }^{\mathrm{b}}$ Average strike-slip rupture.

\section{Viscoelastic Loading cycle}

50 year time frame is generally exceeded by both the modeled static and viscoelastic stress changes, and for this reason it is omitted.

[11] The impact of time-dependent $\Delta \sigma_{f}$ on earthquakes can be measured by the advance or delay in occurrence time of an earthquake resulting from the relaxation component of $\Delta \sigma_{f}$. Chéry et al. [2001a] showed that the impact can be substantial by considering a model of stress evolution in which the background loading process and the relaxation process are independent. We arrive at the same conclusion in the case that the loading and relaxation processes are coupled. In the framework of a strike-slip earthquake cycle on a fault embedded within a two-dimensional shear zone [Pollitz, 2001], the evolution of fault-parallel shear stress $\Delta \tau$ with time at a location near the fault can be calculated (solid curve Figure 4). The sublithospheric Maxwell relaxation time in this example has been chosen to be much shorter than the repeat time of the earthquake in order to bring out aspects of strong time dependence. The slope of the $\Delta \tau$ versus time curve near the beginning of a cycle (short dashed line in Figure 4) represents the apparent loading rate that might be measured by a GPS experiment. The slope near the end of the cycle (long dashed line in Figure 4) represents the background loading rate of the shear zone effectively after all relaxation effects from earlier earthquakes have decayed to a negligible level. The longshort dashed line represents the average interseismic loading rate, which coincides with the asymptotic loading rate in the limit of very large sublithosphere viscosity [Pollitz, 2001]. The interseismic stress evolution in the absence of postseismic relaxation would be governed by this line. If a secondary fault is located at this point, then a simple model of failure would prescribe the time of failure as the time when stress has reached a fixed critical value $\sigma_{c}$. In the absence of postseismic relaxation, the time to failure is $T_{\text {asymptotic }}$, occurring relatively late in the cycle. However, when viscoelastic relaxation is factored in, the time to failure is at an earlier time $T_{V E}$. This example shows that an advance in time to failure, relative to the nonrelaxing case, is produced when postseismic $\Delta \tau$ is positive; the reverse obviously holds when postseismic $\Delta \tau$ is negative. Our use of the measure $\Delta \sigma_{f}$ is a proxy for a more complicated evaluation of probability of failure of a secondary fault. The use of this simpler measure is justified by the lack of knowledge of detailed properties of the secondary faults. In cases where such knowledge may be gained, a more complicated treatment based on rate and state-depen-
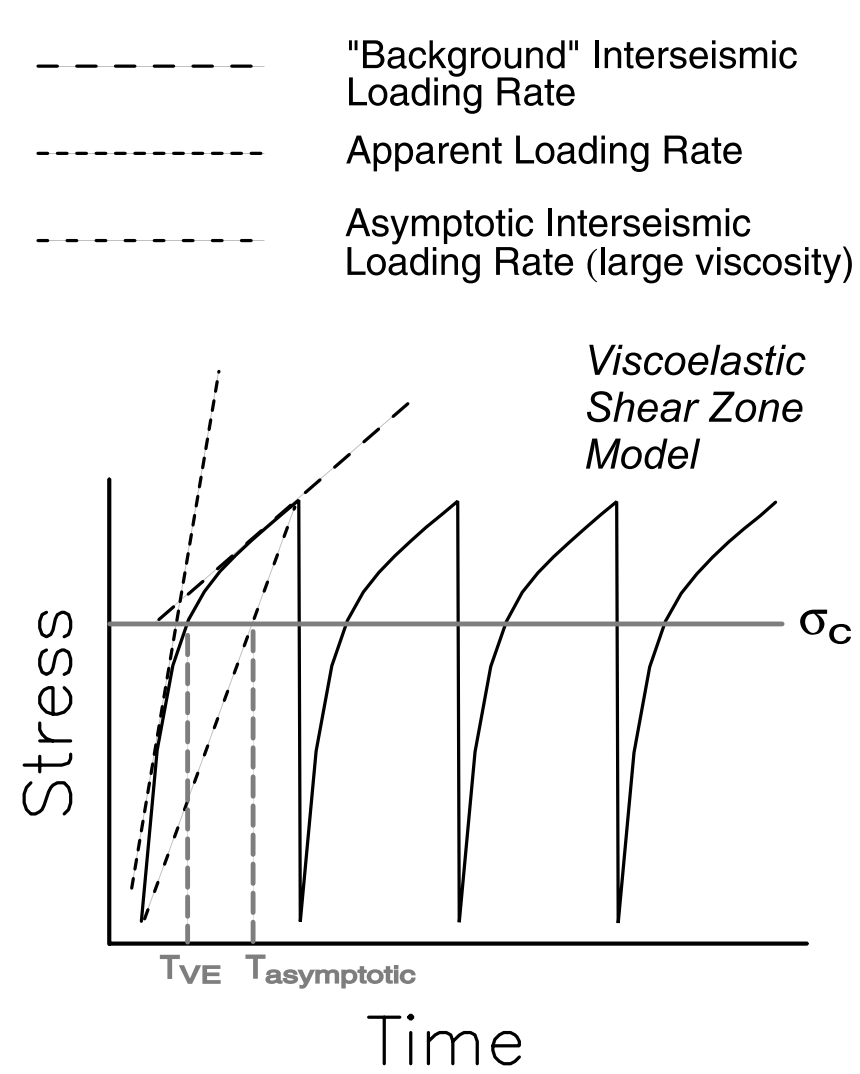

Figure 4. Evolution of fault-parallel shear stress $\Delta \tau$ in a shear zone containing an infinitely long strike-slip fault. This fault is assumed to be embedded in an elastic lithosphere of thickness $H$ overlying a viscoelastic half-space plastosphere of uniform viscosity [Pollitz, 2001]. The half width of the shear zone is $10 \mathrm{H}$. Assuming that the fault undergoes periodic, uniform slip with repeat time $T$, that it penetrates the entire lithosphere, and that the Maxwell relaxation time of the plastosphere is $(1 / 15) \times T$, the evolution of $\Delta \tau$ with time (solid curve) is calculated at a point located a distance $H$ from the fault. Dashed lines indicate the apparent behavior of the viscoelastic system at times early in the seismic cycle, late in the cycle, or the average over the cycle. Given a constant $-\Delta \tau$ failure criterion for a secondary fault at this location, $T_{\text {asymptotic }}$ and $T_{V E}$ indicate the estimated failure time of that fault assuming that the stress evolution is governed, respectively, by the average interseismic velocity or the exact interseismic velocity. 

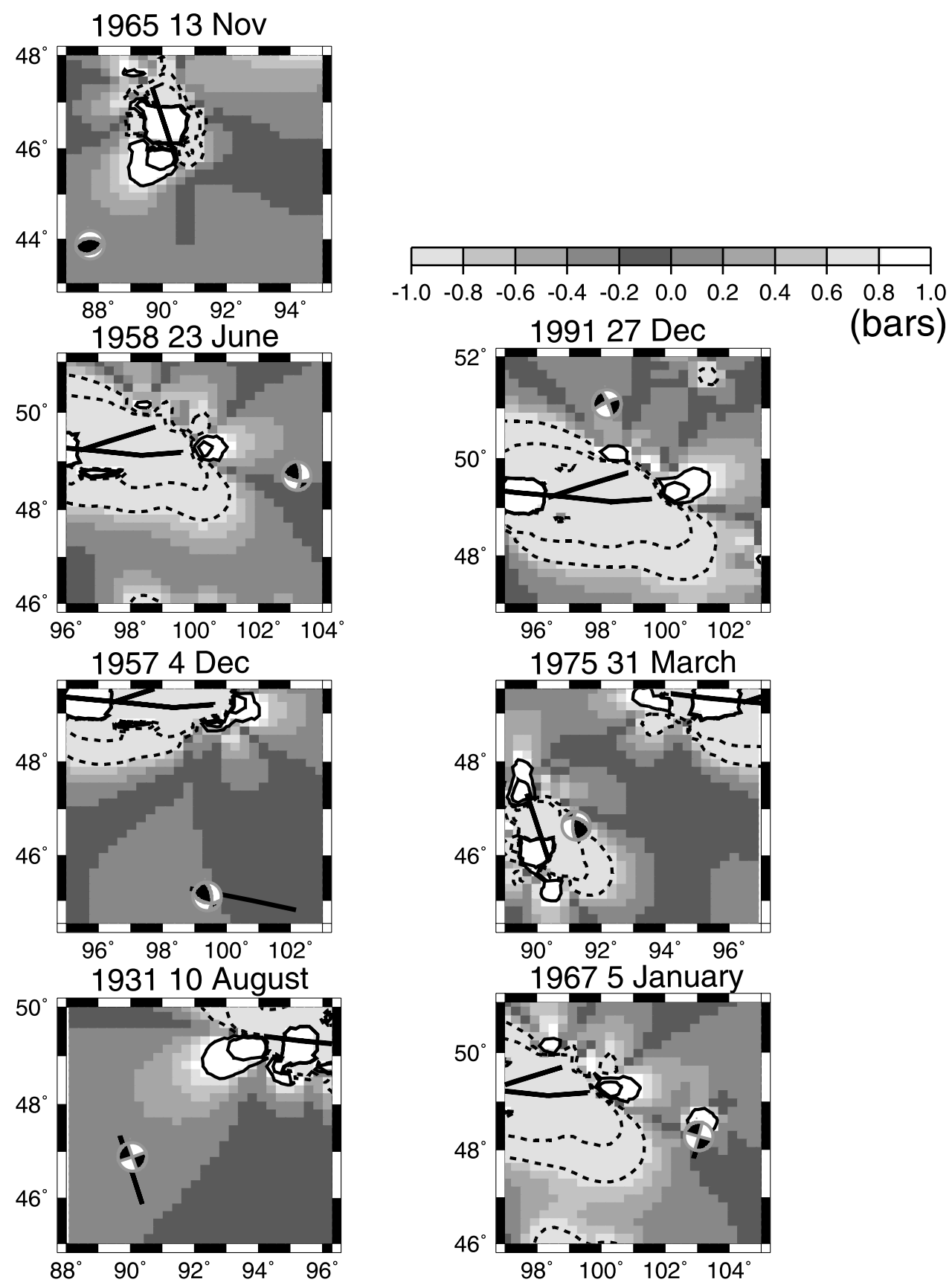

Figure 5. Cumulative static stress change at $20 \mathrm{~km}$ depth evaluated just prior to the occurrence of each of the non-Baikal secondary earthquakes listed in Table 1. $\mu_{\text {eff }}$ is fixed at 0.4 except for the 1957 earthquake for which $\mu_{\text {eff }}=0$. Continuous black contours indicate +1 bar and +3 bar stress changes; dashed contours indicate -1 bar and -3 bar stress change. Thick black line segments indicate fault planes associated with source earthquakes contributing to the calculated deformation. See color version of this figure in the HTML.

dent friction, starting from the estimation of $\Delta \sigma_{f}$, can be successful [Dieterich et al., 2000].

\subsection{Static Stress Change}

[12] Figure 5 shows the cumulative static stress change at $20 \mathrm{~km}$ depth at times just prior to the occurrence of the secondary earthquakes. In Figure 5 and Figures $7-11, \Delta \sigma_{f}$ in each subplot is evaluated for the specific fault geometry of the considered secondary earthquake, as constrained by the indicated focal mechanism. In all cases, the slip plane was chosen as that most consistent with the regional stress field [Baljinnyam et al., 1993; Cunningham, 1998] or the known fault which ruptured. We do not consider that any of the secondary earthquakes are ambiguous in that regard. As discussed later, we also make a natural subdivision of the secondary earthquakes into "Mongolian" (or non-Baikal) earthquakes located outside the Baikal Rift zone and "Baikal" earthquakes located within it. 
[13] It is apparent that static stress changes alone are marginally capable of explaining the twentieth century earthquake pattern. For example, the stress changes in 1931 and 1967 (just before the occurrence of the corresponding earthquakes) are about 0.1 bars. While this stress change is positive, it is at the lower end of the range of $\Delta \sigma_{f}$ known to be correlated with aftershock activity [Stein, 1999]. The static stress changes for other values of $\mu_{\text {eff }}$ have a similar pattern and differ only slightly in magnitude in the regions of interest.

\subsection{Viscoelastic Stress Change}

[14] When the ductility of the lower crust and upper mantle are taken into account, the state of stress in the region evolves continually with time, including the interval between successive primary earthquakes, beginning with the first primary earthquake (Bolnai/Tsetserleg earthquake). Moreover, this process carries the potential to modify the state of stress at remote distances from the primary earthquakes. While the inclusion of viscoelasticity introduces another level of complexity into the stress evolution process, it expands the possibilities for fault interaction in distance and time.

[15] Figure 6 shows the time evolution of normal stress and shear stress resolved on a hypothetical thrust structure located at the 1957 Gobi-Altai epicenter (20 km depth), accounting only for the postseismic contribution of the 1905 earthquake. The distance separating the two ruptures is $\sim 400-500 \mathrm{~km}$. Models $\mathrm{A}$ and $\mathrm{B}$ are as described in section 2, while the "thin channel" model is characterized by $\eta_{c}=10^{18} \mathrm{~Pa}$ s and $\eta_{m}=\infty$. All curves exhibit a buildup of postseismic stress over a period of decades. The buildup on model B, which possesses a stronger crust than the other two models, is the most persistent with time as it doesn't flatten before 1957. The decades long stress buildup is much longer than the material relaxation time(s) in all cases because of the dispersive nature of the viscoelastic relaxation process, the viscoelastic normal modes at longer wavelength being associated with much longer spectral decay times than those at short wavelength [Pollitz, 1997].

[16] Figure 7 shows the stress evolution, evaluated at times just before the occurrence of seven (out of the nine listed in Table 1) secondary earthquakes unassociated with the Lake Baikal region, on model A, which is characterized by a weak mantle and a weak lower crust. Comparison with the pattern of static stress change shows that $\Delta \sigma_{f}$ at both the $1931 \mathrm{Fu}$ Yun and 1967 Mogod ruptures are further increased by the addition of cumulative 1905-1931 or 1905-1967 relaxation, respectively. Both these and four other non-Baikal earthquake rupture zones are situated in regions of $\Delta \sigma_{f} \simeq 0.5$ or greater. Figure 8 shows the stress evolution on model $\mathrm{B}$, characterized by a weak mantle and a strong lower crust. The patterns of $\Delta \sigma_{f}$ are changed little and again point to a substantial contribution of postseismic stress accumulation. This result is qualitatively not very sensitive to the value of $\eta_{c}$.

[17] Table 2 summarizes the Coulomb stress changes at the epicenters of the secondary earthquakes just before their respective times of occurrence. Among the secondary strikeslip earthquakes, both the 1957 and 1975 earthquakes are located in a weakly positive $\Delta \sigma_{f}$ region. We shall discuss the 1957 rupture in greater detail in section 4 . The static $\Delta \sigma_{f}$
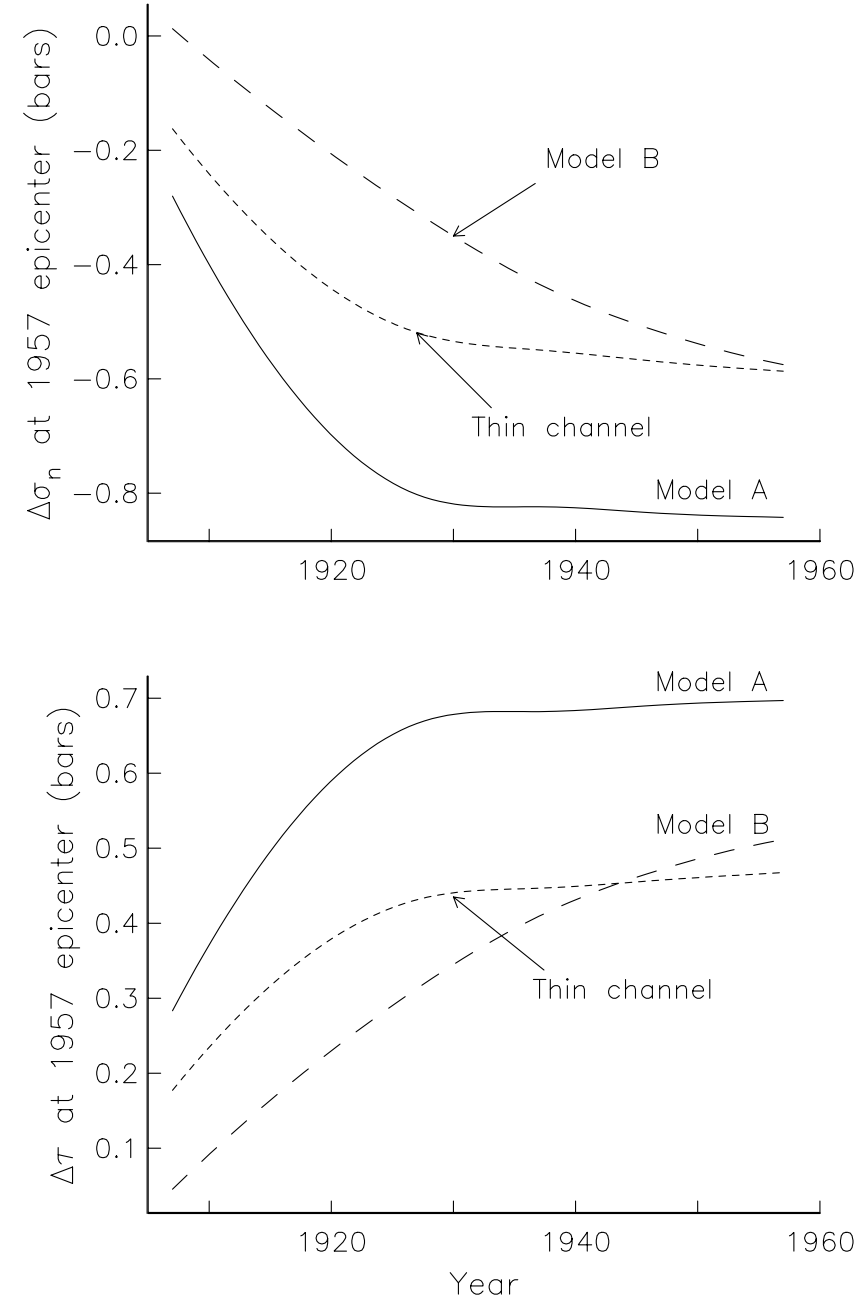

Figure 6. Cumulative viscoelastic stress change imparted by the 1905 Bolnai earthquake on the epicenter of the 1957 Gobi-Altai earthquake (depth $20 \mathrm{~km}$ ) resolved on a hypothetical thrust structure with strike $103^{\circ}$, dip $53^{\circ}$, and rake $90^{\circ}$. Models A and B are as described in Figure 3, while the "thin channel" model is characterized by $\eta_{c}=$ $10^{18} \mathrm{~Pa} \mathrm{~s}$ and $\eta_{m}=\infty$.

pattern in the locality of the 1975 earthquake (Figure 9) is found very sensitive to the details of slip of the $1931 \mathrm{Fu}$ Yun earthquake, which we have assumed to be uniform slip in this study. However, the postseismic contribution to $\Delta \sigma_{f}$ is about 1 bar (Figure 9), helping to bring the future 1975 rupture zone out of the stress shadow of the 1931 earthquake. In spite of the large positive postseismic stress contribution, we judge the 1975 event marginally encouraged by the stress changes from preceding earthquakes.

\subsection{Lake Baikal Area Earthquakes}

[18] Unlike the twentieth century earthquakes which occurred in Mongolia and western China, those earthquakes which occurred in or near the Baikal Rift zone are not correlated with the static and/or viscoelastic stress change. This is demonstrated in Figure 10 for the 1950 Mondy and 1959 south Lake Baikal earthquakes. With a coefficient of friction of 0.8 the 1959 earthquake can be weakly encouraged $\left(\Delta \sigma_{f} \sim 0.1\right.$ bar), but this level of $\Delta \sigma_{f}$ is still well 

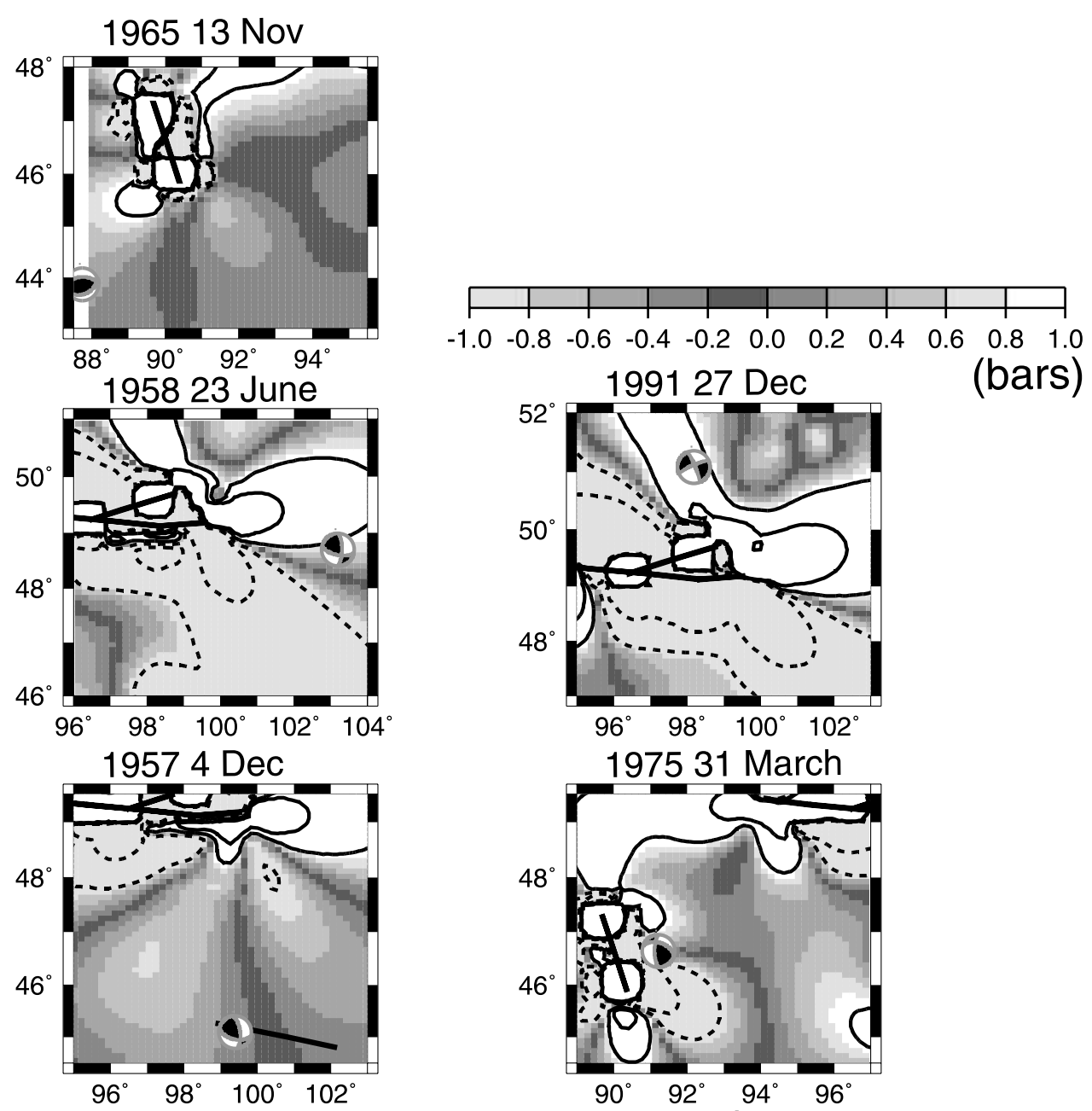

(bars)
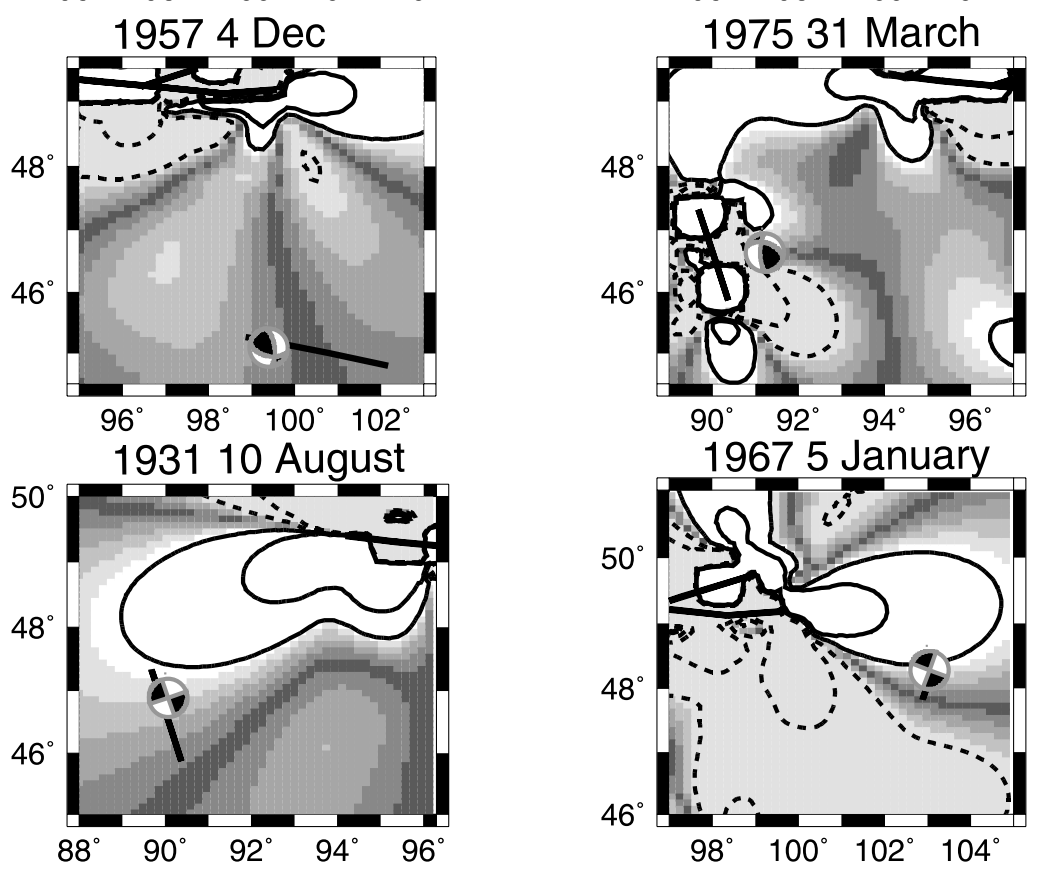

Figure 7. Cumulative static plus viscoelastic stress change evaluated on model A (weak mantle, weak crust) just prior to the occurrence of each of the non-Baikal secondary earthquakes listed in Table 1. Other conventions are as in Figure 5. See color version of this figure in the HTML.

below the level achieved for the Mongolian earthquakes. The 1950 earthquake is associated with $\Delta \sigma_{f} \sim 0.4$ bar provided that a strong crust rheology (i.e., model B) applies. This may well apply to the Lake Baikal region [Déverchère et al., 2001], though any apparent correlation between the 1950 earthquake and the 1905 earthquake is likely purely fortuitous. We attribute the lack of correlation between the 1950 and 1959 earthquakes with calculated $\Delta \sigma_{f}$ to the different tectonic regimes in which the Mongolian earthquakes and Baikal earthquakes are situated. While most of west central Mongolia is characterized by a maximum principle stress which is horizontal under NE-SW compression, the Baikal Rift area is characterized by a minimum principle stress which is horizontal under NW-SE extension. In addition, the regions exhibit substantial differences in heat flow [Khutorskoy and Yarmoluk, 1989; Lysak, 1992], mantle seismic velocities [Levshin et al., 1996; Villaseñor et al., 2001; Friederich, 2003], and style of deformation [Cunningham, 1998]. These differences suggest a difference in viscoelastic structure beneath these regions which is not accounted for by the one-dimensional viscoelastic model used here, which is most applicable to west central Mongolia. 
$196513 \mathrm{Nov}$
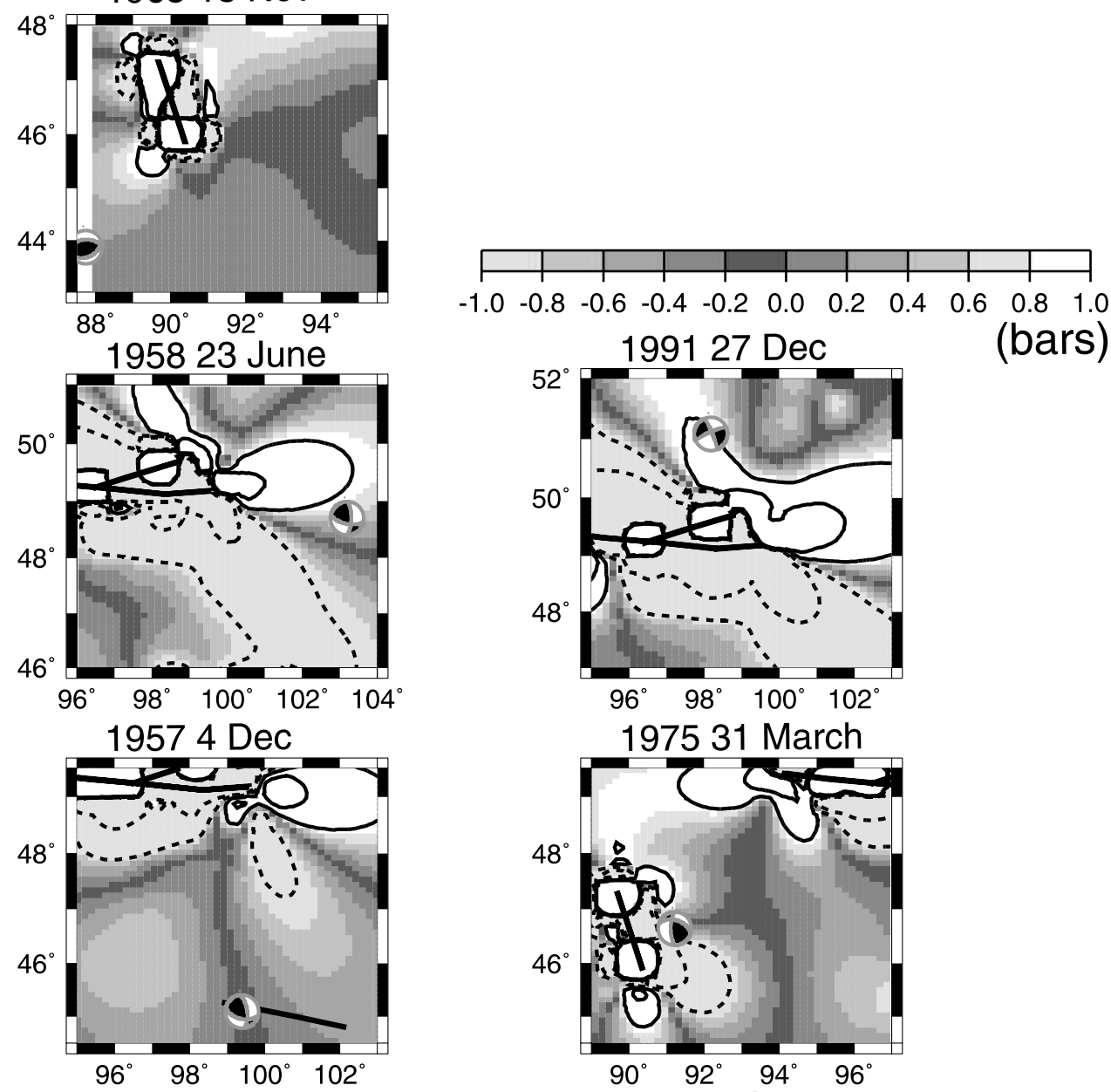
193110 August

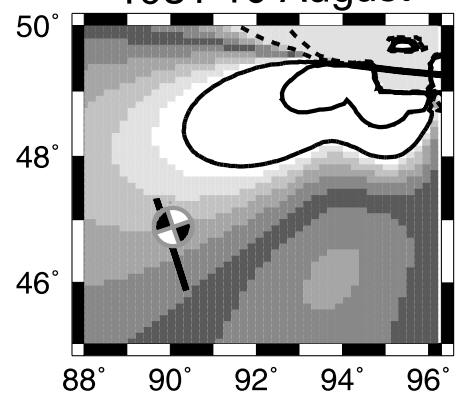

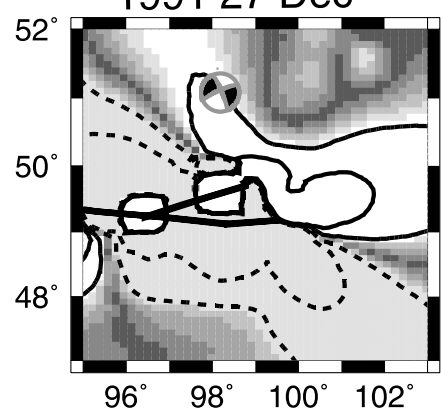
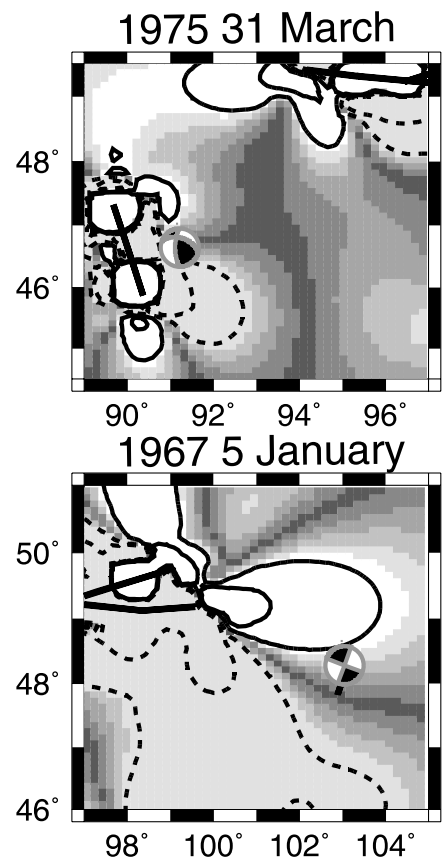

Figure 8. Cumulative static plus viscoelastic stress change evaluated on model B (weak mantle, strong crust) just prior to the occurrence of each of the non-Baikal secondary earthquakes listed in Table 1. Other conventions as in Figure 5. See color version of this figure in the HTML.

Consequently, we do not regard the lack of correlation exhibited by the 1950 and 1959 events to represent a failure of the viscoelastic stress triggering mechanism.

\section{Discussion}

[19] The results presented in section 3.4 and Table 2 demonstrate that the viscoelastic stress transfer mechanism, in the framework of a simple Coulomb failure function, generally encouraged the occurrence of twentieth century earthquakes in Mongolia and western China at a level of several tenths of a bar. The obtained patterns of $\Delta \sigma_{f}$ are robust with respect to a wide range of $\eta_{c}$. We find the patterns of $\Delta \sigma_{f}$ are also robust with respect to a change in $\eta_{m}$, but within narrower limits, i.e., $8 \times 10^{17}$ to $3 \times 10^{18} \mathrm{~Pa} \mathrm{~s}$, the range that admits a good fit to the instantaneous GPS velocity field [Vergnolle et al., 2003]. Within that range the patterns of $\Delta \sigma_{f}$ are similar but the amplitudes vary by 10 to $40 \%$ depending on the specific secondary fault and the elapsed time since the nearest primary earthquake.

[20] The stress change just prior to the 1957 Gobi-Altai earthquake is sensitive to whether it is evaluated using secondary fault parameters appropriate for the nucleation point, for the entire fault, or for reverse slip on the Gurvan 
Table 2. Stress Changes of Non-Baikal Earthquakes

\begin{tabular}{ccccc}
\hline $\begin{array}{c}\text { Earthquake } \\
\text { Year }\end{array}$ & $\mu_{\text {eff }}$ & Coseismic & $\begin{array}{c}\text { Postseismic } \\
\text { Model A }\end{array}$ & $\begin{array}{c}\text { Postseismic } \\
\text { Model B }\end{array}$ \\
\hline 1931 & 0.0 & -0.11 & -0.01 & -0.01 \\
1931 & 0.4 & 0.06 & 0.65 & 0.43 \\
1931 & 0.8 & 0.23 & 1.31 & 0.87 \\
1957 & 0.0 & $0.05^{\mathrm{a}}, 0.03^{\mathrm{b}}$ & $0.14^{\mathrm{a}}, 0.52^{\mathrm{b}}$ & $-0.05^{\mathrm{a}}, 0.35^{\mathrm{b}}$ \\
1957 & 0.4 & $-0.03^{\mathrm{a}}, 0.01^{\mathrm{b}}$ & $-0.37^{\mathrm{a}}, 0.13^{\mathrm{b}}$ & $-0.47^{\mathrm{a}},-0.23^{\mathrm{b}}$ \\
1957 & 0.8 & $-0.11^{\mathrm{a}},-0.01^{\mathrm{b}}$ & $-0.88^{\mathrm{a}},-0.26^{\mathrm{b}}$ & $-0.89^{\mathrm{a}},-0.81^{\mathrm{b}}$ \\
1958 & 0.0 & 0.09 & 1.25 & 0.89 \\
1958 & 0.4 & 0.02 & 0.72 & 0.53 \\
1958 & 0.8 & -0.05 & 0.19 & 0.17 \\
1965 & 0.0 & -0.03 & -0.14 & -0.03 \\
1965 & 0.4 & 0.04 & 0.28 & 0.21 \\
1965 & 0.8 & 0.11 & 0.70 & 0.45 \\
1967 & 0.0 & 0.11 & 1.40 & 1.18 \\
1967 & 0.4 & 0.02 & 0.61 & 0.64 \\
1967 & 0.8 & -0.07 & -0.18 & 0.10 \\
1975 & 0.0 & -1.06 & -0.62 & -0.13 \\
1975 & 0.4 & -1.05 & 0.13 & 0.00 \\
1975 & 0.8 & -1.05 & 0.88 & 0.13 \\
1991 & 0.0 & -0.25 & -0.06 & -0.14 \\
1991 & 0.4 & 0.12 & 1.70 & 1.15 \\
1991 & 0.8 & 0.49 & 3.46 & 2.44 \\
\hline
\end{tabular}

${ }^{\mathrm{a}}$ First-motion mechanism of Okal [1976]

${ }^{\mathrm{b}}$ Thrust mechanism (strike $103^{\circ}$, dip $53^{\circ}$, rake $90^{\circ}$ ).

Bulag or Bayan Tsagaan nuruu thrust faults [Kurushin et al., 1997]. This is demonstrated in Figure 11, where all three cases are considered. It is clear that the hypothesis of viscoelastic (or static) triggering of the entire rupture, which is predominantly strike-slip motion, fails. However, the greater the amount of thrust motion involving east-west trending faults is accommodated on the secondary fault, the greater the triggering capability. This is seen through the other two cases in Figure 11 by the greater $\Delta \sigma_{f}$ obtained for the cases in which a minor amount of thrust motion is present (the first motion solution of Okal [1976]) or pure reverse slip on an east-west trending, $45^{\circ}$ dipping secondary fault representing, for example, the Bayan Tsagaan nuruu thrust fault. These $\Delta \sigma_{f}$ patterns assume $\mu_{\text {eff }}=0$ because larger $\mu_{\text {eff }}$ leads to reduced $\Delta \sigma_{f}$ due to increased clamping since $\Delta \sigma_{n}$ is generally negative. If viscoelastic stress transfer, primarily from the 1905 Bolnai earthquake, is at least in part responsible for triggering the 1957 Gobi-Altai earthquake, then our analysis suggests that the 1957 earthquake may have nucleated with rupture of a thrust segment with a low effective coefficient of friction. This is consistent with the scenario proposed by Kurushin et al. [1997] that the GobiAltai earthquake may have initiated with rupture of the Tsagaan nuruu thrust fault at the western extremity of the Bogd fault and then propagated east as a predominantly leftlateral strike-slip rupture. A low coefficient of friction could be associated with elevated pore fluid pressure in the fault zone.

[21] The modeled stress changes of $0.2-1.7$ bar are small relative to the stress drop of a large earthquake. With a stress accumulation rate of $0.003 \mathrm{bars} / \mathrm{yr}$ (inferred from the strain field measured by GPS [Vergnolle et al., 2003]) and a stress drop of order 10 bars, the associated clock advance of encouraged events is of the order hundreds of years, much smaller than the recurrence times of thousands of years thought to characterize at least the Bogd and Bolnai faults. However, an objective test of the Coulomb triggering hypothesis is not the size of the clock advance relative to the recurrence time, but rather the probability that the secondary events in question would have occurred by chance. Specifically, we evaluate the probability that (1) 6 of 7 randomly distributed secondary events would lie in a positive $\Delta \sigma_{f}$ region and (2) the two largest secondary earthquakes (1931 Fu Yun and 1957 Gobi-Altai) could have both occurred within a 86 year $(1905-1991)$ time interval by chance. The first case concerns the spatial pattern of secondary events and is addressed with a simple binomial test. If all non-Baikal events except the 1975 event are considered associated with positive $\Delta \sigma_{f}$, then the probability that 6 of 7 events would lie in a positive $\Delta \sigma_{f}$ region is $6 \%$. The second case concerns the temporal pattern of secondary events. The recurrence time of the Gobi-Altai event is of order 3000 years [Ritz et al., 2003]. The recurrence time of the Fu Yun event is unknown, but the ratio of $\sim 0.5$ between the slip of the 1931 and 1957 earthquakes suggests a rough value $\sim 1500$ years.
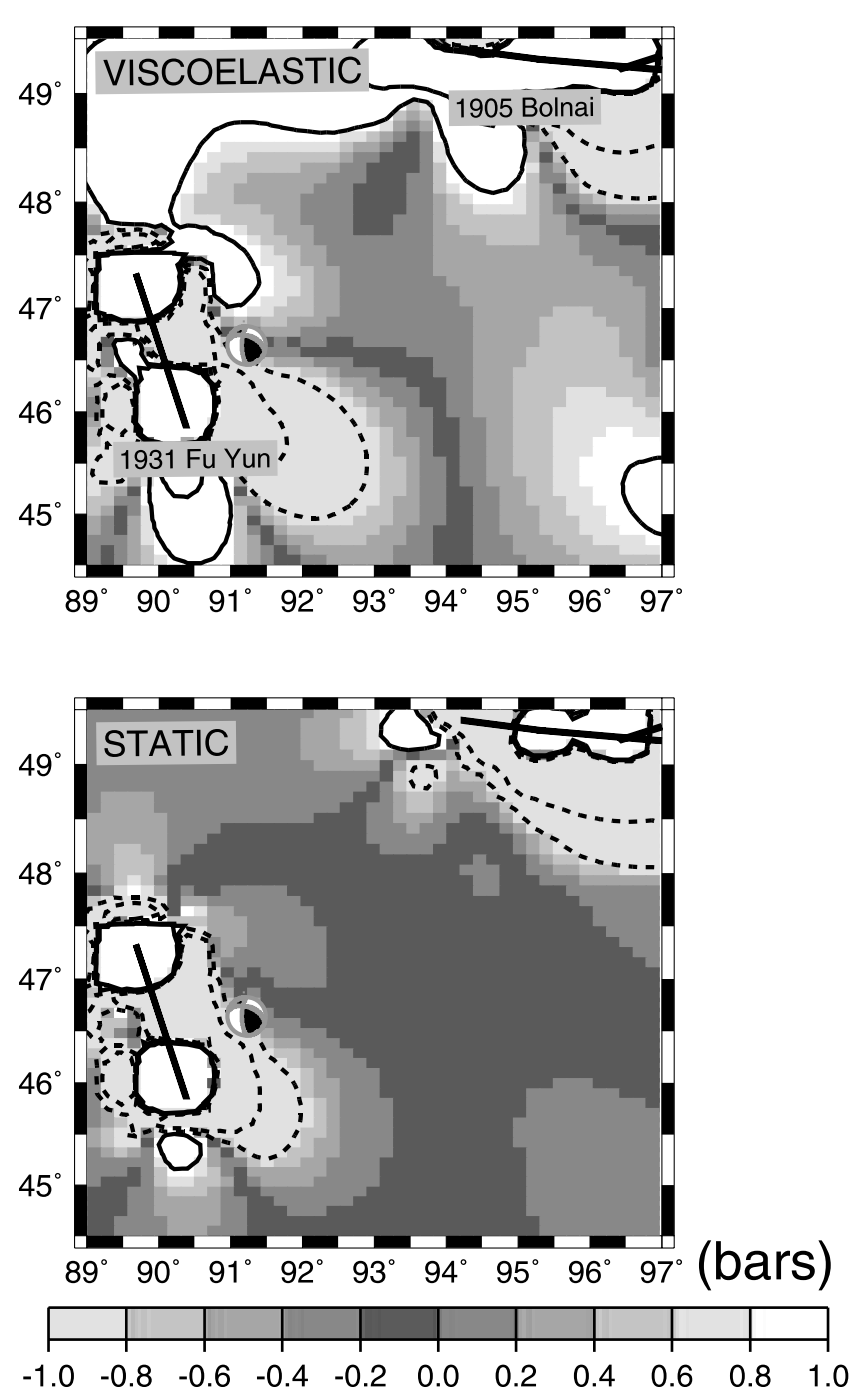

Figure 9. (bottom) Cumulative static stress change and (top) static plus viscoelastic stress change evaluated on model A just prior to the occurrence of the 1975 earthquake. The addition of about +1 bar from viscoelastic relaxation may have helped the future 1975 epicentral region emerge from the stress shadow cast by the Fu Yun earthquake. See color version of this figure in the HTML. 

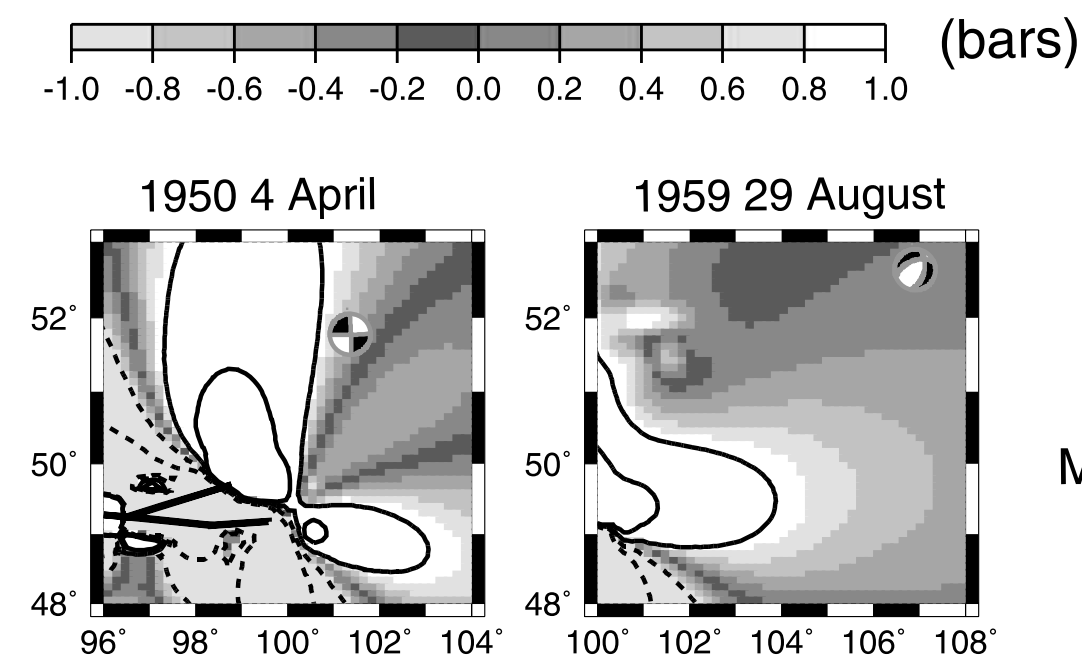

MODEL B
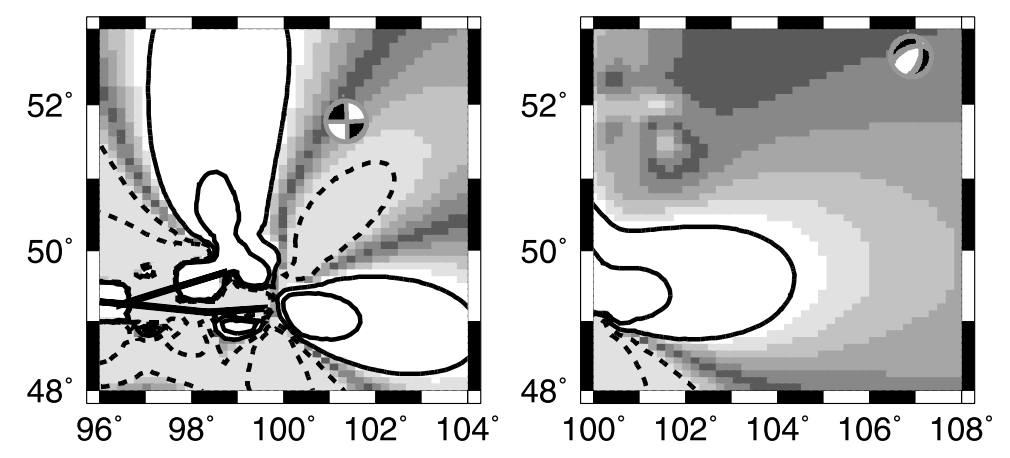

MODEL A

Figure 10. Cumulative static plus viscoelastic stress change with $\mu_{\mathrm{eff}}=0.8$ on both model $\mathrm{A}$ and model $\mathrm{B}$ evaluated just prior to the occurrence of each of the two Baikal secondary earthquakes listed in Table 1. See color version of this figure in the HTML.

The marginal probability of occurrence of these two earthquakes alone within an 86 year time interval is $0.14 \%$. These results, in combination with the fact that Coulomb stress changes of $\geq 0.1$ bars are causally linked with secondary earthquake occurrence elsewhere [Reasenberg and Simpson, 1992; King et al., 1994; Hardebeck et al., 1998; Stein, 1999], suggest a causal relationship between post1905 stress changes and the triggering of twentieth century earthquakes.

[22] The decay rate of viscoelastic relaxation following the various primary earthquakes is not as rapid as would be judged by the Maxwell relaxation time of the mantle ( 2 years for $\eta_{m}=10^{18} \mathrm{~Pa} \mathrm{~s}$ ). This is because the viscoelastic decay spectrum is highly dispersive, the larger wavelengths generally being associated with longer decay times than the shorter wavelengths [Pollitz, 1997]. At $400 \mathrm{~km}$ wavelength, the decay times of the dominant spheroidal and toroidal mode components on model A are 62 and 6 years, respectively.

[23] Chéry et al. [2001b, Figure 4] suggest that the behavior of the interacting fault system in Mongolia is due to the major faults in question arriving at stress states close to the failure threshold nearly simultaneously. Although their suggestion was reached using seismicity catalogues tied to a nondispersive stress transfer process, it deserves further scrutiny. It implies that the viscoelastic relaxation process is an essential ingredient for fault system behavior that obeys self-organized criticality over many seismic cycles. The relaxation process may then be seen as a long wavelength stress-smoothing mechanism since it would bring distant faults closer to failure with an inherent lag time. A regional system that has reached a state of selforganized criticality is characterized by relatively large stress heterogeneity and short range seismicity correlations early in a cycle but relative stress homogeneity and long range correlations late in a cycle [Bowman et al., 1998; Sammis and Smith, 1999; Klein et al., 2000]. The same phenomenon is exhibited for the behavior of a single fault zone in intermittent criticality [Ben-Zion et al., 2003]. The development of long range correlations in fault-scale systems results from the smoothing of long wavelength stress fluctuations by numerous smaller events preceding a large system-sized event [Sornette and Sammis, 1995]. It is an open question what may produce stress uniformity on a broad regional scale. If, however, the Chéry et al. [2001b] hypothesis of viscoelastic stress transfer is correct, then it must be large enough to gradually bring the individual major fault zone cycles into synchroneity, i.e., the viscoelastic stress changes must be at least a fraction of the total stress buildup over a cycle. In order to be effective, it seems necessary that communication among the main causative faults (i.e., the relaxation process) take place much more rapidly than the interevent cycle time [Chéry et al., 2001b]. The viscoelastic stress transfer model presented here is 

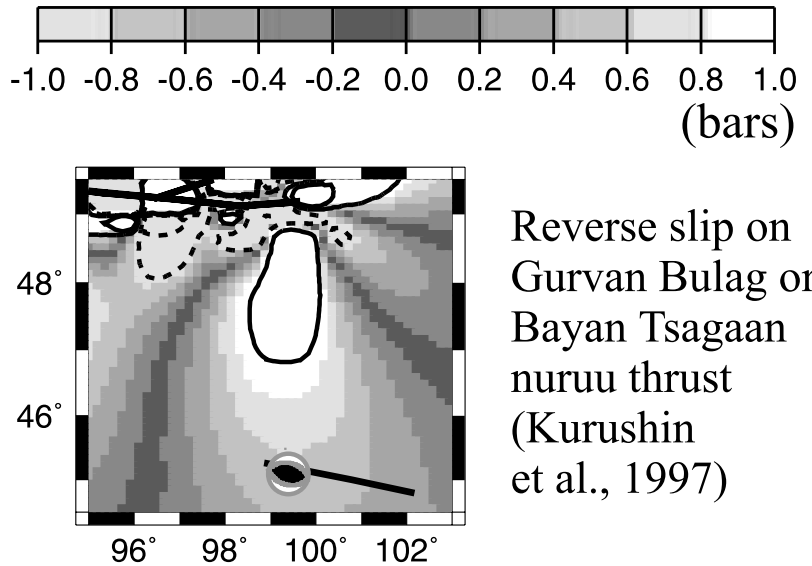

Reverse slip on Gurvan Bulag or Bayan Tsagaan nuruu thrust (Kurushin et al., 1997)

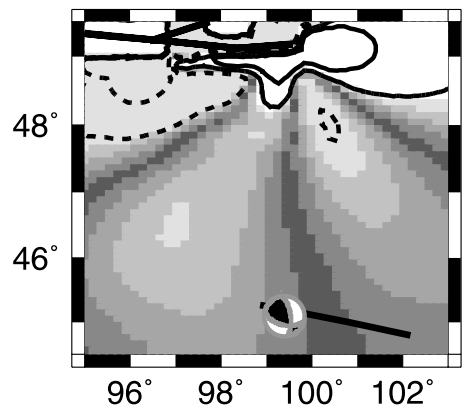

\section{First motion solution (Okal, 1976)}

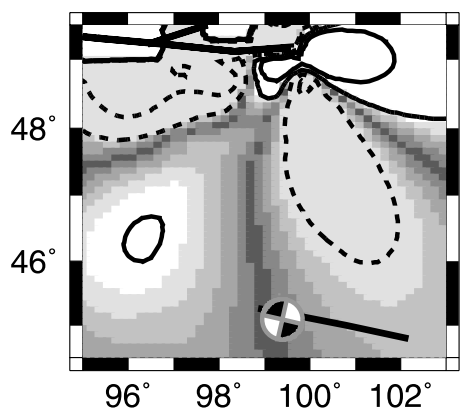

\section{Strike-slip motion (average rupture)}

Figure 11. Cumulative static plus viscoelastic stress change on model A evaluated just prior to the occurrence of the 1957 Gobi-Altai earthquake. Coulomb stress change $\Delta \sigma_{f}$ is evaluated for each of three candidate secondary fault geometries, indicated by the respective focal mechanism solutions. In all cases, $\mu_{\mathrm{eff}}=0$. See color version of this figure in the HTML.

consistent with their hypothesis. We further suggest that it is necessary to consider the totality of large-scale faulting in central Asia in order to understand the behavior of the Mongolian system.

\section{Conclusions}

[24] The locations of several large $(M \geq 6)$ twentieth century earthquakes in Mongolia and western China are well correlated with positive stress changes associated with preceding twentieth century earthquakes, beginning with the M8.4 1905 Bolnai earthquake. We identify viscoelastic relaxation of the lower crust and upper mantle following major earthquakes as the most important contributor to the regional stress evolution.

[25] This mechanism results in several tenths of a bar stress changes at the nucleation point of a future (potentially triggered) earthquake. Static stress changes associated with the primary earthquakes are small because of the typical source to triggered event distance (100-400 km). Background loading over the considered time interval is also comparatively small.

[26] The efficiency of viscoelastic relaxation arises from the existence of comparatively strong upper crust underlain by a weak mantle and possibly a weak lower crust beneath Mongolia in our viscoelastic structure. If our interpretation is correct, then the occurrence of large regional earthquakes are to a large extent the response to preceding continental earthquakes. Lag times of several decades typically separate the occurrences of primary and secondary (triggered) earthquakes. We believe that this is due primarily to the characteristic relaxation times of the long wavelength components of the postseismic deformation field on the viscoelastic model. It may to a certain extent also reflect a characteristic timescale of secondary faults under a rate and state-dependent friction law [Dieterich et al., 2000]. In this case, however, increased probability of earthquake occurrence requires a driving stress perturbation of sufficient magnitude (i.e., several tenths of a bar). As remarked by Chéry et al. [2001b], only viscoelastic relaxation appears capable of fulfilling this requirement at long triggering distances.

[27] Acknowledgments. We thank Ross Stein, David Schwartz, Heidi Stenner, Paul Reasenberg, Ruth Harris, and Dave Hill (USGS Menlo Park) for helpful advice, and David Schwartz and Bob Simpson their reviews of a preliminary draft. We gratefully acknowledge the constructive comments of two anonymous reviewers and the Associate Editor. This research was supported by the INSU-CNRS ("Intérieur de la Terre" program), and the French Ministry for Research ("ACI Catastrophes Naturelles”). UMR Géosciences Azur, CNRS-UNSA, contribution 592.

\section{References}

Astiz, L., P. M. Shearer, and D. Agnew, Precise relocations and stress change calculations for the Upland earthquake sequence in southern California, J. Geophys. Res., 105, 2937-2953, 2000.

Baljinnyam, I., et al., Ruptures of major earthquakes and active deformation in Mongolia and its surroundings, Mem. Geol. Soc. Am., 181, 62 pp., 1993.

Bayasgalan, A., Active tectonics of Mongolia, Ph.D. thesis, 180 pp., Trinity Coll., Cambridge, U.K., 1999.

Bayasgalan, A., and J. A. Jackson, A re-assessment of the faulting in the 1967 Mogod earthquakes in Mongolia, Geophys. J. Int., 138, 784-800, 1999.

Bennett, R. A., R. E. Reilinger, W. Rodi, and Y. Li, Coseismic fault slip associated with the $1992 M_{w}$ 6.1 Joshua Tree, California, earthquake: Implications for the Joshua Tree-Landers earthquake sequence, J. Geophys. Res., 100, 6443-6461, 1995.

Ben-Zion, Y., M. Eneva, and Y. Liu, Large earthquake cycles and intermittent criticality on heterogeneous faults due to evolving stress and seismicity, J. Geophys. Res., 108(B6), 2307, doi:10.1029/ 2002JB002121, 2003.

Bowman, D. D., G. Ouillon, C. G. Sammis, A. Sornettte, and D. Sornette, An observational test of the critical earthquake concept, J. Geophys. Res., 103, 24,359-24,372, 1998

Calais, E., M. Vergnolle, J. Déverchère, V. San'kov, A. Lukhnev, and $\mathrm{S}$. Amarjargal, Are post-seismic effects of the $\mathrm{M}=8.4$ Bolnay earthquake (July 23, 1905) still influencing GPS velocities in the Mongolia-Baikal area?, Geophys. J. Int., 149, 157-168, 2002.

Calais, E., M. Vergnolle, V. San'kov, A. Lukhnev, A. Miroshnitchenko, $\mathrm{S}$. Amarjargal, and J. Déverchère, GPS measurements of crustal deformation in the Baikal-Mongolia area (1994-2002): Implications for current kinematics of Asia, J. Geophys. Res., 108, doi:10.1029/ 2002JB002373, in press, 2003. 
Chapman, D. S., and K. P. Furlong, Thermal state of the continental lower crust, in Continental Lower Crust, Dev. Geotectonics, vol. 23, edited by D. M. Fountain, R. Arculus, and R. M. Kay, pp. 179-199, Elsevier Sci., New York, 1992

Chéry, J., S. Merkel, and S. Bouissou, A physical basis for time clustering of large earthquakes, Bull. Seismol. Soc. Am., 91, 1685-1693, 2001 a.

Chéry, J., S. Carretier, and J. F. Ritz, Postseismic stress transfer explains time clustering of large earthquakes in Mongolia, Earth Planet. Sci. Lett., 94, 277-286, 2001b.

Cunningham, W. D., Lithospheric controls on late Cenozoic construction of the Mongolian Altai, Tectonics, 17, 891-902, 1998

Delouis, B., J. Déverchère, V. Melnikova, N. Radziminovitch, L. Loncke, C. Larroque, J.-F. Ritz, and V. San'kov, A reappraisal of the 1950 $\left(M_{w} 6.9\right)$ Mondy earthquake, Siberia, and its relationship to the strain pattern at the southwestern end of the Baikal rift zone, Terra Nova, 14(6), $491-500,2002$

Deng, J. S., K. Hudnut, M. Gurnis, and E. Hauksson, Stress loading from viscous flow in the lower crust and triggering of aftershocks following the 1994 Northridge California, earthquake, Geophys. Res. Lett., 26 , 3209-3212, 1999.

Déverchère, J., C. Petit, N. Gileva, N. Radziminovitch, V. Melnikova, and V. San'kov, Depth distribution of earthquakes in the Baikal rift and its implications for the rheology of the lithosphere, Geophys. J. Int., 146, 714-730, 2001

Dieterich, J., V. Cayol, and P. Okubo, The use of earthquake rate changes as a stress meter at Kilauea volcano, Nature, 408, 457-460, 2000.

Dodge, D. A., G. C. Beroza, and W. L. Ellsworth, Foreshock sequence of the 1992 Landers, California, earthquake and its implications for earthquake nucleation, J. Geophys. Res., 100, 9865-9880, 1995.

Doser, D. I., Faulting within the western Baikal rift as characterized by earthquake studies, Tectonophysics, 196, 87-107, 1991.

Du, Y., and A. Aydin, Stress transfer during three sequential moderate earthquakes along the central Calaveras fault, California, J. Geophys. Res., 98, 9947-9962, 1993.

Freed, A. M., and J. Lin, Delayed triggering of the 1999 Hector Mine earthquake by viscoelastic stress transfer, Nature, 411, 180-183, 2001.

Friederich, W., The $S$-velocity structure of the East Asian mantle from inversion of shear and surface waveforms, Geophys. J. Int., 153, $88-$ 102, 2003.

Gross, S. J., and R. Bürgmann, Rate and state of background stress estimated from the aftershocks of the 1989 Loma Prieta earthquake, J. Geophys. Res., 103, 4915-4927, 1998.

Gross, S., and C. Kisslinger, Estimating tectonic stress rate and state with Landers aftershocks, J. Geophys. Res., 102, 7603-7612, 1997.

Hardebeck, J. L., J. J. Nazareth, and E. Hauksson, The static stress change triggering model: Constraints from two southern California aftershock sequences, J. Geophys. Res., 103, 24,427-24,437, 1998.

Harris, R. A., Introduction to special section: Stress triggers, stress shadows, and implications for seismic hazard, J. Geophys. Res., 103, 24,347-24,358, 1998.

Hill, D. P., et al., Seismicity remotely triggered by the magnitude 7.3 Landers, California, earthquake, Science, 260, 1617-1623, 1993.

Ionov, D., S. Y. O'Reilly, and W. L. Griffin, A geotherm and lithospheric section for central Mongolia (Tariat region), in Mantle Dynamics and Plate Interactions in East Asia, Geodyn. Ser, vol. 27, edited by M. J. F. Flower et al., pp. 127-153, AGU, Washington, D. C., 1998.

Ivins, E. R., Transient creep of a composite lower crust: 2 . A polymineralic basis for rapidly evolving postseismic deformation modes, J. Geophys. Res., 101, 28,005-28,028, 1996.

Jaume, S. C., and L. R. Sykes, Changes in state of stress on the southern San Andreas fault resulting from the California earthquake sequence of April to June 1992, Science, 258, 1325-1328, 1992.

Kaufmann, G., and F. Amelung, Reservoir-induced deformation and continental rheology in the vicinity of Lake Mead, Nevada, J. Geophys. Res., $105,16,341-16,358,2000$

Khilko, S. D., R. A. Kurushin, V. M. Kotchetkov, L. A. Misharina, V. I Melnikova, N. A. Gileva, S. V. Lastochkin, I. Baljinnyam, and D. Monhoo, Strong earthquakes, paleoseismogeological and macroseismic data, in Earthquakes and the Base for Seismic Zoning of Mongolia(in Russian), Trans. Joint Sov.-Mongolian Res. Geol. Sci. Exped., vol. 41, pp. 19-83, Nauka, Moscow, 1985.

Khutorskoy, M. D., and V. V. Yarmoluk, Heat flow, structure and evolution of the lithosphere of Mongolia, Tectonophysics, 164, 315-322, 1989.

King, G. C., R. S. Stein, and J. Lin, Static stress changes and the triggering of earthquakes, Bull. Seismol. Soc. Am., 84, 935-953, 1994.

Klein, W., M. Anghel, C. D. Ferguson, J. B. Rundle, and J. S. Sá Martins, Statistical analysis of a model for earthquake faults with long-range stress transfer, in GeoComplexity and the Physics of Earthquakes, Geophys Monogr. Ser., vol. 120, edited by J. B. Rundle, D. L. Turcotte, and W. Klein, pp. 43-71, AGU, Washington, D. C., 2000.
Kopylova, M. G., S. Y. O'Reilly, and Y. S. Genshaft, Thermal state of the lithosphere beneath Central Mongolia: Evidence from deep-seated xenoliths from the Shavaryn-Saram volcanic centre in the Tariat depression, Hangai, Mongolia, Lithos, 36, 243-255, 1995.

Kurushin, R. A., A. Bayasgalan, M. Olziybat, B. Enhtuvshin, P. Molnar, Ch. Bayarsayhan, K. Hudnut, and J. Lin, The surface rupture of the 1957 Gobi-Altay, Mongolia, earthquake, Spec. Pap. Geol. Soc. Am., 320, 143 pp., 1997.

Lachenbruch, A. H., and A. McGarr, Stress and heat flow on the San Andreas fault, U.S. Geol. Surv. Prof Pap., 1515, 261-277, 1990.

Levshin, A. L., M. H. Ritzwoller, and S. S. Smith, Group velocity variations across Eurasia, in Proceedings of the 18th Seismic Research Symposium on Monitoring a Comprehensive Test Ban Treaty, pp. 70-79, Phillips Lab., Hanscom AFB, Mass., 1996.

Lysak, S. V., Heat flow variations in continental rifts, Tectonophysics, 208, 309-323, 1992

Mackwell, S. J., M. E. Zimmerman, and D. L. Kohlstedt, High-temperature deformation of dry diabase with application to tectonics on Venus, J Geophys. Res, 103, 975-984, 1998

Nishimura, T., and W. Thatcher, Rheology of the lithosphere inferred from postseismic uplift following the 1959 Hebgen Lake earthquake, J. Geophys. Res., 108(B8), 2389, doi:10.1029/2002JB002191, 2003

Okal, E., A surface-wave investigation of the rupture mechanism of the Gobi-Altai (December 4, 1957) earthquake, Phys. Earth Planet. Inter. $12,319-328,1976$

Okal, E., The July 9 and 23, 1905, Mongolian earthquakes: A surface wave investigation, Earth Planet. Sci. Lett., 34, 326-331, 1977.

Petit, C., J. Déverchère, E. Calais, V. San'kov, and D. Fairhead, Deep structure and mechanical behavior of the lithosphere in the HangaiHovsgol region, Mongolia: New constraints from gravity modelling, Earth Planet. Sci. Lett., 197, 133-149, 2002.

Pollitz, F. F., Coseismic deformation from earthquake faulting on a layered spherical Earth, Geophys. J. Int., 125, 1-14, 1996.

Pollitz, F. F., Gravitational-viscoelastic postseismic relaxation on a layered spherical Earth, J. Geophys. Res., 102, 17,921-17,941, 1997.

Pollitz, F. F., Viscoelastic shear zone model of a strike-slip earthquake cycle, J. Geophys. Res., 106, 26,541-26,560, 2001.

Pollitz, F. F., Stress triggering of the 1999 Hector Mine earthquake by transient deformation following the 1992 Landers earthquake, Bull. Seismol. Soc. Am., 92, 1487-1496, 2002.

Pollitz, F. F., and I. S. Sacks, The 1995 Kobe, Japan, earthquake: A longdelayed aftershock of the offshore 1944 Tonankai and 1946 Nankaido earthquakes, Bull. Seismol. Soc. Am., 87, 1-10, 1997.

Pollitz, F. F., R. Bürgmann, and B. Romanowicz, Viscosity of oceanic asthenosphere inferred from remote triggering of earthquakes, Science, 280, 1245-1249, 1998 .

Pollitz, F. F., C. Wicks, and W. Thatcher, Mantle flow beneath a continental strike-slip fault: Postseismic deformation after the 1999 Hector Mine earthquake, Science, 293, 1814-1818, 2001

Price, E., and R. Bürgmann, Interaction between the 1992 Landers and the 1999 Hector Mine, California earthquakes from space geodesy, boundary element modeling, and time-dependent friction, Bull. Seismol. Soc. Am., 92, 1450-1469, 2002.

Reasenberg, P. A., and R. W. Simpson, Response of regional seismicity to the static stress change produced by the Loma Prieta earthquake, Science, $255,1687-1690,1992$

Ritz, J.-F., et al., Late Pleistocene to Holocene slip rates for the Gurvan Bulag thrust fault (Gobi-Altay, Mongolia) estimated with $10 \mathrm{Be}$ dates, J. Geophys. Res., 108(B3), 2162, doi:10.1029/2001JB000553, 2003

Rydelek, P. A., and I. S. Sacks, Asthenospheric viscosity and stress diffusion: A mechanism to explain correlated earthquakes and surface deformations in northeast Japan, Geophys. J. Int., 100, 39-58, 1990.

Rydelek, P. A., and I. S. Sacks, Migration of large earthquakes along the San Jacinto fault: Stress diffusion from the 1857 Fort Tejon earthquake, Geophys. Res. Lett., 28, 3079-3082, 2001.

Sammis, C. G., and S. W. Smith, Seismic cycles and the evolution of stress correlation in cellular automoton models of finite fault networks, Pure Appl. Geophys., 155, 307-334, 1999.

Sanders, C. O., Interaction of the San Jacinto and San Andreas fault zones, southern California: Triggered earthquake migration and coupled recurrence intervals, Science, 260, 973-976, 1993.

Sornette, D., and C. G. Sammis, Complex critical exponents from renormalization group theory of earthquakes: Implications for earthquake predictions, J. Phys., 5, 607-619, 1995.

Stein, R. S., The role of stress transfer in earthquake occurrence, Nature, $402,605-609,1999$

Stosch, H. G., D. A. Ionov, I. S. Puchtel, S. J. G. Galer, and A. Sharpouri, Lower crustal xenoliths from Mongolia and their bearing on the nature of the deep crust beneath central Asia, Lithos, 36, 227-242, 1995. 
Tapponnier, P., and P. Molnar, Active faulting and Cenozoic tectonics of the Tien Shan, Mongolia, and Baykal regions, J. Geophys. Res., 84, 34253459, 1979.

Vergnolle, M., F. Pollitz, and E. Calais, Constraints on the viscosity of the continental crust and mantle from GPS measurements and postseismic deformation models in western Mongolia, J. Geophys. Res., 108, doi:10.1029/2002JB002374, in press, 2003.

Villaseñor, A., M. H. Ritzwoller, A. L. Levshin, M. P. Barmin, E. R. Engdahl, W. Spakman, and J. Trampert, Shear velocity structure of central Eurasia from inversion of surface wave velocities, Phys. Earth Planet. Inter., 123, 169-184, 2001.
Zeng, Y., Viscoelastic stress-triggering of the 1999 Hector Mine earthquake by the 1992 Landers earthquake, Geophys. Res. Lett., 28, 3007-3010, 2001 .

E. Calais, Department of Earth and Atmospheric Sciences, Purdue University, West Lafayette, IN 47907-1397, USA. (ecalais@purdue.edu)

F. Pollitz, U.S. Geological Survey, 345 Middlefield Road, MS 977, Menlo Park, CA 94025, USA. (fpollitz@usgs.gov)

M. Vergnolle, UMR 6526 CNRS Géosciences Azur, University of Nice, 250 Rue A. Einstein, F-06560 Valbonne, France. (vergno@geoazur.unice.fr) 